\title{
Value of endoscopic features for diagnosis of Helicobacter pylori induced gastritis and their correlation with histologic aspects
}

\author{
Yazbek Amani, Moussawy Sahar, Sweid Amal, Matar Rasha and Khalil Ali* \\ Department of Medicine, Division of Gastroenterology, Al Zahraa Hospital University Medical Center, Jnah, Beirut, Lebanon
}

\begin{abstract}
Background: Helicobacter pylori infection is a major risk factor for a variety of gastric diseases. Although many tests were developed for its diagnosis, unfortunately all of them have their limitations and issues. Recent studies highlighted the usefulness of macroscopic findings during endoscopy in diagnosis of $H$. pylori. However, the results were contradictory and confusing.

Objectives: Thus, we conducted this study to determine the value of endoscopy in this regard, and to define a correlation between endoscopic findings and histologic findings.

Methods: We started a prospective study on 200 endoscopies done for adult patients in Al- Zahraa Hospital University Medical Center (ZHUMC) beginning from January $1^{\text {st }}, 2018$ to June $30^{\text {th }}, 2018$. Patients included are those undergoing diagnostic EGD for dyspeptia. Patients having previous history of $H$. pylori infection or being treated with anti-secretory medications or antibiotics within last four weeks were excluded.

Abnormal endoscopic findings were classified as erythema, edema, erosion (flat/raised); rugal hypertrophy, rugal atrophy, nodularity and mosaic pattern (cobblestone appearance).

Histologic examination was made by one pathologist and results were classified as antral inflammation, mucosal atrophy, intestinal metaplasia and neutrophil activity.

Results: Out of 200 patients, 121 were excluded, and in the 79 remaining, we found that only the mosaic pattern showed high diagnostic yield with a specificity, sensitivity and PPV of $100 \%$.
\end{abstract}

However, all endoscopic findings failed to predict a specific histomorphological pattern.

Conclusion: We suggest that the mosaic appearance is a reliable indicator for the presence $H$. pylori infection without predicting a specific underlying histological pattern.

\section{Introduction}

H.pylori infection is a common chronic bacterial infection residing in the stomach of more than $50 \%$ of humans worldwide $[1,2]$. It is contracted in the early childhood and persists indefinitely unless specific treatment is applied $[3,4]$.

Thousands of researches about $H$. pylori, conducted through 30 years, demonstrated that this bacterium, by its colonization of the human stomach, induces mucosal inflammation and a variety of upper gastrointestinal disorders, such as chronic gastritis, peptic ulcer disease in particular duodenal ulcer, gastric mucosa-associated lymphoid tissue (MALT) lymphoma, non-ulcer dyspepsia, gastric cancer and other rare gastric conditions. But its culpability is suspected yet not been approved in other clinical settings, especially non-ulcer (functional) dyspepsia, unexplained iron deficiency anemia, rosacea, coronary artery disease, hepatic encephalopathy, psoriasis, idiopathic thrombocytopenic purpura (ITP) [7,12].

\section{Objectives}

As we previously discussed in this work, Helicobacter pylori infection appears to be the key risk factor for a variety of gastric lesions and diseases mainly gastritis, and lately it was classified as carcinogen bacterium because of its proven role in the development of gastric adenocarcinoma.

However, this infection can be cured successfully in $90 \%$ of cases with an antibiotic regimen, thereby healing definitely multiple disease states, decreasing their recurrence rate and eliminating the risk for developing one of the most fatal neoplasms.

Therefore, it became an urge need to get a diagnostic tool characterized by a low cost so it can be applied for diagnosis and screening of millions of people worldwide, also it should be simple, reliable, giving reproducible, accurate and rapid results.

${ }^{*}$ Correspondence to: Khalil Ali, Department of Medicine, Division of Gastroenterology, Al Zahraa Hospital University Medical Center, Jnah, Beirut, Lebanon, Tel: 009613051039, E-mail: drakhalil29@gmail.com

Key words: histomorphological pattern, H. pylori, gastric diseases, duodenal ulcer, gastric mucosa

Received: November 09, 2020; Accepted: November 23, 2020; Published: November 26, 2020 
Although many tests were developed for this purpose and were been continuously improving in the last decades, unfortunately all of them have their limitations and issues.

Recent studies highlighted that some macroscopic findings noted during EGD were highly related to some histomorphological changes and were highly suggestive of the presence of H.pylori infection but unfortunately their results were confusing and non conclusive.

In our study, we try to determine the value of endoscopic macroscopic diagnosis of $H$. pylori infection, so if the endoscopists could determine the infection state of his patient on the field, the patient can be discharged immediately from the endoscopy section with the accurate treatment, thereby decreasing time and money wasting, improving management and rendering the situation easier for the physician.

Another objective of our study is to determine an association, if such one is present, between macroscopic findings on EGD and histomorphological findings on biopsy.

\section{Material and methods}

\section{Subjects}

A total of 200 endoscopies done for adult patients in ZHUMC beginning from January $1^{\text {st }}, 2018$ to June $30^{\text {th }}, 2018$ were interpreted prospectively. The cases were randomly chosen (inpatient or outpatient, from both sexes, no specific socioeconomic status and no specific region in lebanon) on the basis of the only inclusion criteria: undergoing a diagnostic EGD for dyspepsia. A patient suffers from dyspepsia if he has either epigastric pain, heartbun, nausea, vomiting, flatulence, eructation, fullness after meals, early satiety or abdominal distention, regardless of the severity of these symptoms.

According to our predetermined protocol, every patient having the below criteria was excluded from the sudy:

The exclusion criteria are:

- Previous history of H.pylori infection.

- Antisecretory medication use within last four weeks to the EGD including PPI, Anti-H2 medications or bismuth containing compound.

- Antibiotic (against H.pylori) treatment within last four weeks.

- After review of endoscopic results, patients having gastric or duodenal ulcer on EGD, duodenitis or esophagitis were excluded from the study.

Patients with endoscopically normal looking mucosa were not also included in the study because the aim of our study is to determine endoscopic findings related to H.pylori induced gastritis.

\section{Endoscopic procedure}

Endoscopy was performed after sedation of the patient with $5 \mathrm{mg}$ midazolam and local anesthesia of the oropharynx with $1 \%$ xylocaine spray.

A full endoscopic evaluation of the esophagus, stomach and duodenum were performed in all patients by single advanced physician (>5000 endoscopy).

Endoscopic findings were classified according to present criteria as erythema, edema, erosion (flat/raised), rugal hypertrophy, rugal atrophy, nodularity and mosaic pattern (cobblestone appearance).
The most common dyspeptic symptom was epigastric pain, followed by heartburn, fullness after meals, eructation, early satiety, and vomiting.

\section{Diagnosis}

H. pylori infection status was evaluated by histology and RUT in all patients.

For this purpose, two biopsies were obtained, one from the corpus, the other from the antrum. Before sending the biopsy specimens for histologic assessment, a piece of biopsy was used to accomplish RUT for diagnosis and confirmation of H.pylori infection status.

Histologic examination was made by one pathologist who was blind to the endoscopic findings. The purpose was to detect $H$. pylori infection, determine gastric histomorphological changes induced by the infection, and classify them according to the updated Sydney System as antral inflammation, mucosal atrophy, intestinal metaplasia and neutrophil activity.

\section{Statistical analysis}

The results were analysed statistically, to determine the sensitivity, specificity, PPV, NPV and statistical significance (calculated by Chi square test) of macroscopic features in diagnosing $H$. pylori status of infection and to determine any correlation between endoscopic findings and histomorphological findings.

\section{Results}

Of a total of 200 cases reviewed retrospectively over the period extending from January $1^{\text {st }}, 2018$ to June 30st, 2018, 83 patients were excluded from the study because they had one or more of the exclusion criteria described above. Another group of 31 patients was excluded because of missing data in their medical record.

7 patients had normal appearing mucosa on EGD and there were not included in statistical analysis.

Out of the 79 remaining patients, 33 (41.77\%) were male and 46 (58.23\%) were female with a female to male ratio of 1.4: 1 .

The patient's age ranged from 15 years to 88 years with a mean age of 44.84 years (Figure 1 ).

As shown by the above diagram, the highest percentage of infection was found in the age groups [13-38] and [39-58] in both males and females ( $15.19 \%$ and $16.46 \%$ versus $21.52 \%$ and $18.99 \%$ respectively). On the other hand, extreme age groups [10-19] and [59-69] showed the less percentages of infection in both males and females $(0.00 \% \& 0.00 \%$ versus $6.33 \% \& 1.27 \%$ respectively)

In our study, 29 (36.71\%) patients were smokers and 50(63.29\%) were nonsmokers; 4 patients $(5.06 \%)$ were alcohol drinkers versus 75 (94.94\%) were not drinkers.

45 patients $(56.96 \%)$ were diagnosed to have $H$. pylori positive gastritis while $34(33.04 \%)$ were $H$. pylori negative gastritis.

Figure 2 summarizes the results described above, dividing the patients in two groups:

H.pylori positive and H.pylori negative gastritis; and showing their distribution according to: gender; age class; tobacco smoking and alcohol consumption. 


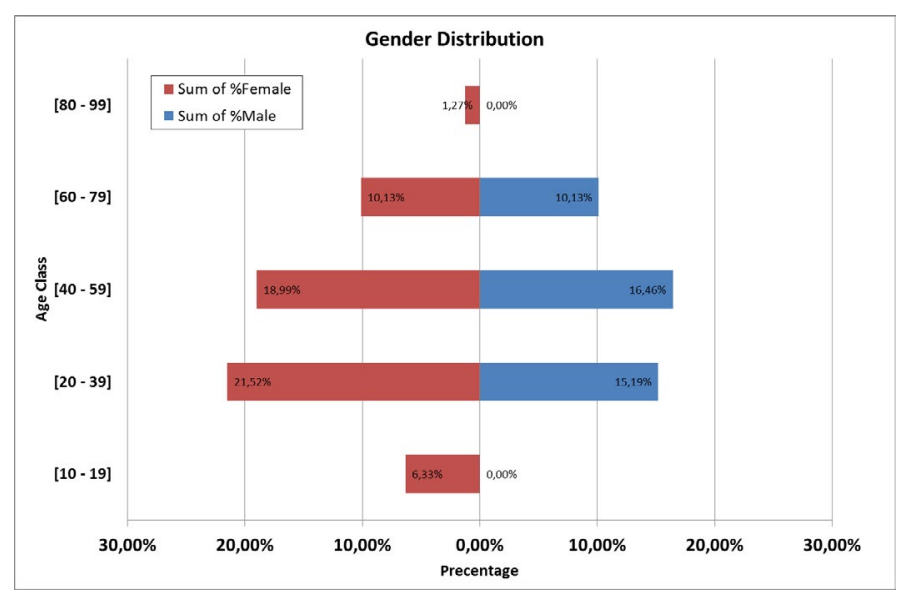

Figure 1. Diagram showing patient's distribution based on gender and age class, and the percentage of each class

\begin{tabular}{|c|c|c|c|c|c|}
\hline & & Total & & H. Pyllori & $\mathrm{No} \mathrm{H}$ Pylori \\
\hline \multirow{2}{*}{ 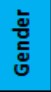 } & Female & $46(58.23 \%)$ & $\rightarrow \rightarrow \rightarrow$ & $24(52.17 \%)$ & $22(47.83 \%)$ \\
\hline & Male & 33 (41.77\%) & $\rightarrow \rightarrow \rightarrow$ & $21(63.63 \%)$ & $12(36.37 \%)$ \\
\hline \multirow{5}{*}{ 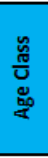 } & {$[10-19]$} & $5(6.33 \%)$ & $\rightarrow \rightarrow \rightarrow$ & $0(0 \%)$ & $5(100 \%)$ \\
\hline & {$[20-39]$} & $29(21.52 \%)$ & $\rightarrow \rightarrow \rightarrow$ & $17(58.62 \%)$ & \begin{tabular}{|l|}
$12(41.38 \%)$ \\
\end{tabular} \\
\hline & [40 - 59] & 28 (35.44\%) & $\rightarrow \rightarrow \rightarrow$ & $18(64.28 \%)$ & $10(35.72 \%)$ \\
\hline & [60 - 79] & $16(20.25 \%)$ & $\rightarrow \rightarrow \rightarrow$ & $10(62.50 \%)$ & \begin{tabular}{|l|}
$6(37.50 \%)$ \\
\end{tabular} \\
\hline & [80 - 99] & \begin{tabular}{|l|}
$1(1.27 \%)$ \\
\end{tabular} & $\rightarrow \rightarrow \rightarrow$ & $0(0 \%)$ & $1(100 \%)$ \\
\hline \multirow{4}{*}{$\begin{array}{l}\frac{0}{50} \\
\frac{50}{x}\end{array}$} & Smokers & $29(36.71 \%)$ & $\rightarrow \rightarrow \rightarrow$ & $16(55.17 \%)$ & $13(44.83 \%)$ \\
\hline & No Smokers & $50(63.29 \%)$ & $\rightarrow \rightarrow \rightarrow$ & $29(58 \%)$ & $21(42 \%)$ \\
\hline & Drinkers & $4(5.06 \%)$ & $\rightarrow \rightarrow \rightarrow$ & $3(75 \%)$ & $1(25 \%)$ \\
\hline & No Drinkers & 75 (94.94\%) & $\rightarrow \rightarrow \rightarrow$ & $42(66 \%)$ & $33(44 \%)$ \\
\hline & $\rightarrow \rightarrow \rightarrow$ & $79(100 \%)$ & & $45(56.96 \%)$ & $34(33.04 \%)$ \\
\hline
\end{tabular}

Figure 2. Distribution of patients according to infection status, gender, age, tobacco, and alcohol consumption

As shown by the above figure 2, H. pylori induced gastritis and non- $H$. pylori gastritis have been found in similar percentages in females $(52.17 \%$ versus $47.83 \%)$. In males, gastritis was found mainly due to $H$. pylori $(63.63 \%$ versus $36.37 \%$ in non $H$. pylori gastritis, respectively).

Based on age group criteria, gastritis was also found mainly due to H. pylori in [20-38] and [39-58] (58.62\% and $64.28 \%$ versus 41.38 and $35.72 \%$ in non $H$. pylori gastritis, respectively). Whereas in extreme age groups [10-19] and [58-69] no H. pylori was found (0\%), therefore all gastritis were non $H$. pylori (100\%)

In smoker and non-smoker patients, gastritis was found mainly due to $H$. pylori $(55.17 \%$ and $58 \%$ versus $44.83 \%$ and $42 \%$ in non $H$. pylori gastritis, respectively).

Also, in alcoholic and non-alcoholic patients, gastritis was found mainly due to $H$. pylori, with wide discrepancy compared to non $H$. pylori gastritis ( $75 \%$ and $66 \%$ versus $25 \%$ and $44 \%$, respectively).

In the H. pylori positive gastritis group, the endoscopic and the histologic findings were distributed as following (Figure 3).

- Endoscopic findings: erythema (62\%); mixed findings (more than one finding in the same patient) (22\%); raised erosion (7\%); nodularity (5\%); mosaic pattern (2\%); flat erosion (2\%).
- Histologic findings: Neutrophil activity (73\%); mucosal atrophy (16\%); intestinal metaplasia (9\%); antral inflammation (2\%) (Figure 4).

- In the H. pylori negative gastritis group, the distribution is as following: (Figure 12)

- Endoscopic findings: erythema (70\%); edema (12\%); nodularity (9\%); flat erosion (3\%); raised erosion (3\%); mixed findings (3\%).

- Histologic findings: Antral inflammation (50\%); intestinal metaplasia (32\%); mucosal atrophy (18\%).

- The diagnostic value (sensitivity; specificity, positive and negative predictive values) of macroscopic findings is shown in table 1 .

Subjects with mosaic pattern showed specificity, sensitivity and PPV of $100 \%$, while NPV was only $66 \%$.

In the other hand, patients with raised erosion showed high specificity of $100 \%$ while sensitivity was only about $6 \%$. The correlation between endoscopic and histologic findings are shown in table 2. Neutrophil activity is highly associated with mosaic pattern in $93 \%$ of cases.

\section{Discussion}

In previous studies treating the value of endoscopic diagnosis of $H$. pylori infection, only one test was used for the diagnosis. However accurate diagnosis of this infection is difficult, and one test used could have significant false results; thus, in our study, we combined two tests for this purpose: histology and RUT making the results more accurate and reliable.

In our study, and because no video-based evaluation was performed, we could not observe detailed mucosal patterns and we could not conduct a blind comparison between endoscopic evaluation of mucosa by more endoscopists, which is a limitation of our study.

In the other hand, one of the inconvenient of histologic diagnosis is its intra- and inter-observer variations, and in our study, histologic interpretation was performed by one single pathologist, which is another limitation of the study.

Reviewing some of previous studies, we noted that results have been contradictory. Khakoo et al. [67] evaluated the significance of

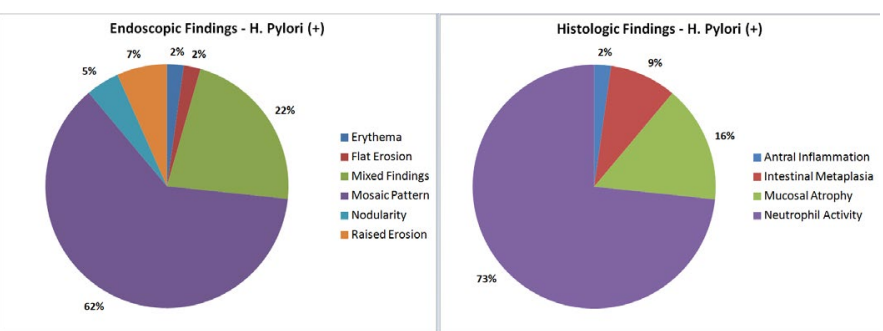

Figure 3. Distribution of and Endoscopic and Histologic Findings in H. pylori positive patients

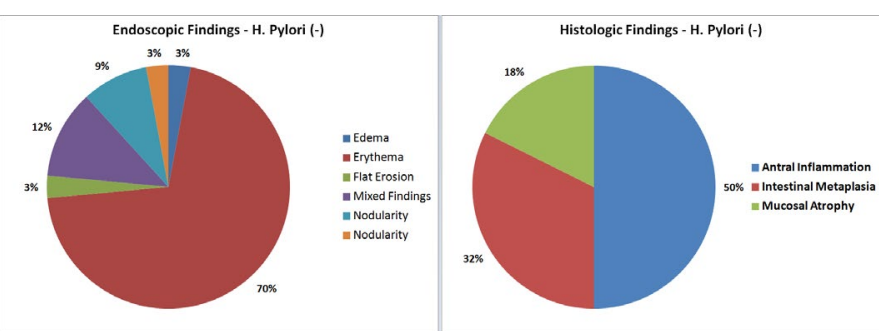

Figure 4. Distribution of Endoscopic and Histologic Findings in H. pylori negative patients 
Table 1. Diagnostic value of endoscopic findings

\begin{tabular}{|l|c|c|c|c|}
\hline Endoscopic Finding & Sensitivity & Specificity & PPV & NPV \\
\hline Mosaic Pattern & $100 \%$ & $100 \%$ & $100 \%$ & $66 \%$ \\
\hline Erythema & $2 \%$ & $29 \%$ & $4 \%$ & $18 \%$ \\
\hline Mixed Findings & $22 \%$ & $88 \%$ & $71 \%$ & $46 \%$ \\
\hline Nodularity & $4 \%$ & $88 \%$ & $33 \%$ & $41 \%$ \\
\hline Raised Erosion & $6 \%$ & $100 \%$ & $100 \%$ & $44 \%$ \\
\hline Flat Erosion & $2 \%$ & $97 \%$ & $50 \%$ & $42 \%$ \\
\hline Edema & $0 \%$ & $97 \%$ & $0 \%$ & $42 \%$ \\
\hline
\end{tabular}

Table 2. Correlation between endoscopic and histologic findings

\begin{tabular}{|l|c|c|c|c|c|}
\hline \multirow{2}{*}{$\begin{array}{l}\text { Endoscopic } \\
\text { Findings }\end{array}$} & $\begin{array}{c}\text { Histological Findings } \\
\text { Neutrophil } \\
\text { Activity }\end{array}$ & $\begin{array}{c}\text { Antral } \\
\text { Inflammation }\end{array}$ & $\begin{array}{c}\text { Intestinal } \\
\text { Metaplasia }\end{array}$ & $\begin{array}{c}\text { Mucosal } \\
\text { Atrophy }\end{array}$ & Total \\
\hline Mosaic Pattern & 26 & 0 & 1 & 1 & 28 \\
\hline Erythema & 0 & 17 & 3 & 5 & 25 \\
\hline Mixed findings & 3 & 1 & 5 & 5 & 14 \\
\hline Nodularity & 1 & 0 & 5 & 0 & 6 \\
\hline Raised Erosions & 2 & 0 & 0 & 1 & 3 \\
\hline Flat Erosions & 1 & 0 & 1 & 0 & 2 \\
\hline Edema & 0 & 0 & 0 & 1 & 1 \\
\hline Total & 33 & 18 & 15 & 13 & 79 \\
\hline
\end{tabular}

the endoscopic classification of gastritis by the updated Sydney system (USS) criteria and obtained a low diagnostic yield of $41.8 \%$. They concluded the inappropriateness of an endoscopic diagnosis of gastritis. Belair et al. [68], and Redeen et al. [69] also concluded inappropriate value of endoscopy in making the diagnosis.

But a higher diagnostic yield of $79.5 \%$ was obtained by Mihara. In fact, their study was conducted in high endemic area. So, the inconsistency in diagnostic yields might be explained by differences in regional disease prevalence.

In the present study, diagnostic yield was relatively high for only one endoscopic feature: the mosaic pattern. Mosaic pattern was the commonest single endoscopic finding (35\%) described.

H. pylori was found in $100 \%$ of cases, making this finding specific and sensitive with a high statistical significance (p-value $<0.001$ ). Also, we found that this pattern was highly linked to the neutrophil activity histologic pattern (92.8\%). However, the result was statistically insignificant (p-value 0.2).

The other findings failed to have a statistical significance in the prediction of $H$. pylori infection status, and in the prediction of histomorphological changes, despite that one pattern, the raised erosion pattern had $100 \%$ specificity.

\section{Conclusion}

As a summary, our study revealed that the diagnostic yield for $H$. pylori infection status was high only for the mosaic appearance pattern, but results were not conclusive for the other patterns. All endoscopic findings failed to predict a specific histomorphological pattern. We suggest that the mosaic appearance on endoscopy is a reliable indicator of the underlying $H$. pylori induced gastritis.

\section{References}

1. Pisani P, Parkin DM, Munoz N (1997) Cancer and infection: estimates of the attributable fraction in 1900. Cancer Epidemiol Biomarkers Prevent 6: 389-400.

2. Taylor DN, Parsonnet J (1995) The epidemiology and natural history of Helicobacter pylori infection. Infections of the gastrointestinal tract. Raven Press, New York, USA. 99: 551-564.
3. Rothenbacher D, Bode G, Brenner H (2002) Dynamics of Helicobacter pylori infection in early childhood in a high-risk group living in Germany: loss of infection higher than acquisition. Aliment Pharmacol Ther 16: 1663-1668. [Crossref]

4. Rowland M, Daly L, Higgins A, Bourke B, Drumm B (2006) Age-specific incidence of Helicobacter pylori. Gastroenterology 130: 65-72. [Crossref]

5. Bardhan PK (1997) Epidemiological features of infection in developing countries. Clin Infect Dis 25: 973-978. [Crossref]

6. Kusters JG, van Vliet AHM, Kuipers EJ (2006) Pathogenesis of Helicobacter pylori Infection. Clinical Microbiology Reviews. (3th edn), University Medical Center, Rotterdam, The Netherlands. 19: 449-490.

7. Lambert JR (1993) The role of Helicobacter pylori in nonulcer dyspepsia. A debate for Gastroenterol Clin North Am 22: 141-151. [Crossref]

8. Lazzaroni M, Bargiggia S, Sangaletti O, Maconi G, Boldorini M, et al. (1996) Eradication of Helicobacter pylori and long-term outcome of functional dyspepsia. A clinical endoscopic study. Dig Dis Sci 41: 1589-1594. [Crossref]

9. Rinaldi V, Zullo A, Diana F, Capocaccia L (1997) Helicobacter pylori, hyperammonemia and hepatic encephalopathy: is there a correlation? Am J Gastroenterol 92: 723-724. [Crossref]

10. Kolibasova K, Tothova I, Baumgartner J, Filo V (1996) Eradication of Helicobacter pylori as the only successful treatment in rosacea. Arch Dermatol 132: 1393. [Crossref]

11. Patel P, Mendall MA, Carrington D, et al. (1995) Association of Helicobacter pylori and Chlamydia pneumoniae infections S8 Parsonnet with coronary heart disease and cardiovascular risk factors. $B M J 311: 711-714$.

12. Sullivan PB, Thomas JE, Wight DG, Strachan DP, Leatham E, et al. (1990) Helicobacter pylori in Gambian children with chronic diarrhoea and malnutrition. Arch Dis Child 65: 189-191. [Crossref]

13. Capella R, Fiocca C, Cornaggia M (1999) Autoimmune gastritis. Gastritis. Philadelphia, USA. pp: 79-96

14. Rugge M, Genta RM (2005) Staging and grading of chronic gastritis. Hum Pathol 36 228-233. [Crossref]

15. Makristathis A, Hirschl AM, Lehours PH, Mégraud F (2004) Diagnosis of Helicobacter pylori Infection. Helicobacter 9: 7-14.

16. O'Keeffe J, Moran AP (2008) Conventional, Regulatory, and Unconventional T Cells in the Immunologic Response to Helicobacter pylor. Helicobacter 13: 1-19. [Crossref]

17. Graham DY, Alpert LC, Smith JL, H. H. Yoshimura HH (1988) Iatrogenic Campylobacter pylori infection is a cause of epidemic achlorhydria. Am J Gastroenterol 83: 974-980. [Crossref]

18. Marshall BJ, Armstrong JA, McGechie DB, Glancy RJ (1985) Attempt to fulfil Koch's postulates for pyloric Campylobacter. Med J Austr 142: 436-439. [Crossref]

19. Morris A, Nicholson G (1987) Ingestion of Campylobacter pyloridis causes gastritis and raised fasting gastric pH. Am J Gastroenterol 82: 192-199. [Crossref]

20. Sobala GM, Crabtree JE, Dixon MF, Schorah CJ, Taylor JD, et al. (1991) Acute Helicobacter pylori infection: clinical features, local and systemic immune response, gastric mucosal histology, and gastric juice ascorbic acid concentrations. Gut 32: 14151418 .

21. Kuipers EJ, Uyterlinde AM, Pena AS, Hazenberg HJ, Bloemena E, et al. (1995) Increase of Helicobacter pylori-associated corpus gastritis during acid suppressive therapy: implications for long-term safety. Am J Gastroenterol 90: 1401-1406.

22. Veldhuyzen van Zanten SOJ, Dixon MF, Lee A (1999) The gastric transitional zones: neglected links between gastroduodenal pathology and Helicobacter ecology. Gastroenterology 116: 1217-1229.

23. Labenz J, Gyenes E, Ruhl GS (1993) Is Helicobacter pylori gastritis a macroscopic finding? Dtsch Med Wochenschr 118: 176-180.

24. Lame L, Cohen H, Sloane R, Marin-Sorensen M, Weinstein WM (1995) Interobserver agreement and predictive value of endoscopic findings for $\mathrm{H}$. pylori and gastritis in normal volunteers. Gastrointest Endosc 42: 420-423. [Crossref]

25. Kuipers EJ, Uyterlinde AM, Pena AS, Roosendaal R, Pals G, et al. (1995) Long-term sequelae of Helicobacter pylori gastritis. Lancet 345: 1525-1528.

26. Sakaki N (1995) Endoscopic diagnosis of gastritis in relation to Helicobacter pylori infection and subjective symptoms. J Clin Gastroenterol 21: S135-S139.

27. Ho YY, Daskalopoulos G (1995) Can you diagnose Helicobacter pylori by macroscopic appearance on endoscopy? (Phase I trial) Gut 1: 4C38 
28. Bah A, Armstrong D, Vouillamoz D, Dorta G, Duroux P, et al. (1995) Endoscopic features of helicobacter pylori gastritis. Endosc 27: 593-596. [Crossref]

29. Tytgat GNJ (1991) The Sydney system: Endoscopic division. Endoscopic appearances in gastritis/duodentitis. J Gastroenterol Hepatol 6: 223-224.

30. Czinn SJ, Dahms BB, Jacobs GH, Kaplan B, Rothstein FC (1986) Campylobacter like organism in association with symptomatic gastritis in children. $J$ Pediatr 109: 80-83. [Crossref]

31. Oderda G, Lerro P, Poli E (1998) Childhood nodular gastritis and Campylobacter pylori. Endosc 20: 86.

32. Drumm B, Sherman P, Cutz E, Karmali M (1987) Association of Compylobacter pylori on the gastric mucosa with antral gastritis in children. $N$ Engl J Med 316: 1557-1561. [Crossref]

33. Gasbarrini A, Franceschi F (2005) Does H. pylori infection play a role in idiopathic thrombocytopenic purpura and in other autoimmune diseases? Am J Gastroenterol 100: 1271-1273. [Crossref]

34. Jackson S, Beck PL, Pineo GF, Poon MC (2005) Helicobacter pylori eradication: novel therapy for immune thrombocytopenic purpura? A review of the literature. $\mathrm{Am} \mathrm{J}$ Hematol $78: 142-150$. [Crossref]

35. Suzuki T, Matsushima M, Masui A, Watanabe K, Takagi A, et al. (2005) Effect of Helicobacter pylori eradication in patients with chronic idiopathic thrombocytopenic purpura — a randomized controlled trial. Am J Gastroenterol 100: 1265-1270. [Crossref]

36. Laine L, Lewin DN, Naritoku W, Estrada R, Cohen H (1996) Prospective comparison of commercially available rapid urease tests for the diagnosis of Helicobacter pylori. Gastrointest Endosc 44: 523-526. [Crossref]

37. Siddique I, Al-Mekhaizeem K, Alateeqi N, Memon A, Hasan F (2008) Diagnosis of Helicobacter pylori: improving the sensitivity of CLOtest by increasing the number of gastric antral biopsies. J Clin Gastroenterol 42: 356. [Crossref]

38. Chey WD, Wong BC (2007) Practice Parameters Committee of the American College of Gastroenterology. American College of Gastroenterology guideline on the management of Helicobacter pylori infection. Am J Gastroenterol 102: 1808. [Crossref]

39. Dixon MF, Genta RM, Yardley JH, Correa P, et al. (1996) Classification and grading of gastritis. The updated Sydney system. Internationalworkshop on the histopathology of gastritis, Houston 1994. Am J Surg Pathol 20: 1161-1181. [Crossref]

40. El-Zimaity HM (2000) Accurate diagnosis of Helicobacter pylori with biopsy. Gastroenterol Clin N Am 29: 863-869. [Crossref]

41. Talley NJ, Vakil N (2005) Practice Parameters Committee of the American College of Gastroenterology. Guidelines for the management of dyspepsia. Am J Gastroenterol 100: 2324-2337.

42. Liu H, Rahman A, Semino-Mora C, Doi SQ, Dubois A (2008) Specific and sensitive detection of $\mathrm{H}$. pylori in biological specimens by real-time RT-PCR and in situ hybridization. PLoS One 3: e2689. [Crossref]

43. Leide-Svegborn S, Stenström K, Olofsson M, Mattsson S, Nilsson LE, et al. (1999) Biokinetics and radiation doses for carbon-14 urea in adults and children undergoing the Helicobacter pylori breath test. Eur J Nucl Med 26: 573. [Crossref]

44. Howden CW, Hunt RH (1998) Guidelines for the management of Helicobacter pylori infection. Ad Hoc Committee on Practice Parameters of the American College of Gastroenterology. Am J Gastroenterol 93: 2330.

45. Perez-Perez GI (2000) Accurate diagnosis of Helicobacter pylori. Culture, including transport. Gastroenterol ClinNAm 29: 879-884.

46. Gisbert JP, Pajares JM (2004) Reviewarticle: 13 C-urea breath test in the diagnosis of Helicobacter pylori infection- a critical review. Aliment Pharmacol Ther 20: 10011017.

47. CheyWD (2000) Accurate diagnosis of Helicobacter pylori. $14 \mathrm{C}$ urea breath test. Gastroenterol Clin N Am 29: 895-902.

48. Steen T, Berstad K, Meling T, Berstad A (1995) Reproducibility of the 14 C-urea breath test repeated after 1 week. Am J Gastroenterol 90: 2103-2105. [Crossref]
49. Leodolter A, Domínguez-Muñoz JE, von Arnim U, Kahl S, Peitz U, et al. (1999) Validity of a modified 13C-urea breath test for pre- and posttreatment diagnosis of Helicobacter pylori infection in the routine clinical setting. Am J Gastroenterol 94: 2100-2104. [Crossref]

50. Montalban C, Norman F (2006) Treatment of gastric mucosaassociated lymphoid tissue lymphoma: Helicobacter pylori eradication and beyond. Expert Rev Anticancer Ther 6: $361-371$.

51. Ho B, Marshall BJ (2000) Accurate diagnosis of Helicobacter pylori. Serologic testing. Gastroenterol Clin N Am 29: 853-862.

52. Loy CT, Irwig LM, Katelaris PH, Talley NJ (1996) Do commercial serological kits for Helicobacter pylori infection differ in accuracy? A meta-analysis. Am J Gastroenterol 91: 1138-1144. [Crossref]

53. Nurgalieva ZZ, Graham DY (2003) Pearls and pitfalls of assessing Helicobacter pylori status. Dig Liver Dis 35: 375-377.

54. Hoang TT, Wheeldon TU, Bengtsson C, Phung DC, Sörberg M (2004) Enzyme linked immunosorbent assay for Helicobacter pylori needs adjustment for the population investigated. J Clin Microbiol 42: 627-630. [Crossref]

55. Gisbert JP, Pajares JM (2004) Stool antigen test for the diagnosis of Helicobacter pylori infection: A systematic review. Helicobacter 9: 347-368.

56. Gisbert JP, de la Morena F, Abraira V (2006) Accuracy of monoclonal stool antigen test for the diagnosis of $\mathrm{H}$. pylori infection: A systematic review and meta-analysis. Am J Gastroenterol 101: 1921-1930.

57. Viara D, Vakil N, Menegatti M, van't Hoff B, Ricci C, et al. (2002) The stool antigen test for detection of Helicobacter pylori after eradication therapy. Ann Intern Med 136: 280-287. [Crossref]

58. Odaka T, Yamaguchi T, Koyama H, Saisho H, Nomura F (2002) Evaluation of the Helicobacter pylori stool antigen test for monitoring eradication therapy. Am J Gastroenterol 97: 594-599. [Crossref]

59. Bravo LE, Realpe JL, Campo C, Mera R, Correa P (1999) Effects of acid suppression and bismuth medications on the performance of diagnostic tests for Helicobacter pylori infection. Am J Gastroenterol 94: 2380-2383. [Crossref]

60. Manes G, Balzano A, Iaquinto G, Ricci C, Piccirillo MM, et al. (2001) Accuracy of the stool antigen test in the diagnosis of Helicobacter pylori infection before treatment and in patients on omeprazole therapy. Aliment Pharmacol Ther 15: 73-79. [Crossref]

61. Grino P, Pascual S, Such J, Casellas JA, Niveiro M, et al. (2003) Comparison of stool immunoassay with standard methods for detection of Helicobacter pylori infection in patients with uppergastrointestinal bleeding of peptic origin. Eur J Gastroenterol Hepatol 15: 525-529. [Crossref]

62. Peitz U, Leodolter A, Kahl S, Agha-Amiri K, Wex T, et al. (2003) Antigen stool test for assessment of Helicobacter pylori infection in patients with upper gastrointestinal bleeding. Aliment Pharmacol Ther 17: 1075-1084. [Crossref]

63. Van Leerdam ME, Van Der Ende A, ten Kate FJW, Rauws EAJ, Tytgat GNJ (2003) Lack of accuracy of the noninvasive Helicobacter pylori stool antigen test in patients with gastroduodenal ulcer bleeding. Am J Gastroenterol 98: 798-801. [Crossref]

64. Lin HJ, Lo WC, Perng CL, Li AFY, Tseng GY, et al. (2004) Helicobacter pylori stool antigen test in patients with bleeding peptic ulcers. Helicobacter 9: 663-638. [Crossref]

65. Vaira D, Malfertheiner P, Mégraud F, Axon AT, Deltenre M, et al. (1999) Diagnosis of Helicobacter pylori infection with a new non-invasive antigen-based assay. HpSA European study group. Lancet 354: 30. [Crossref]

66. Manes G, Balzano A, Iaquinto G, Lombardi G, Balzano A, et al. (2001) Accuracy of stool antigen test in posteradication assessment of Helicobacter pylori infection. Dig Dis Sci 46: 2440. [Crossref]

67. Khakoo SI, Lobo AJ, Shepherd NA, Wilkinson SP (1994) Histological assessment of the Sydney classification of endoscopic gastritis. Gut 35: 1172-1175. [Crossref]

68. Belair PA, Metz DC, Faigel DO, Furth EE (1997) Receiver operator characteristic analysis of endoscopy as a test for gastritis. Dig Dis Sci 42: 2227-2233. [Crossref]

69. Redeen S, Petersson F, Jonsson KA, Borch K (2003) Relationship of gastroscopic features to histological findings in gastritis and Helicobacter pylori infection in a general population sample. Endoscopy 35: 946-950. [Crossref]

Copyright: $\odot 2020$ Yazbek A. This is an open-access article distributed under the terms of the Creative Commons Attribution License, which permits unrestricted use, distribution, and reproduction in any medium, provided the original author and source are credited. 